\title{
FINITE ELEMENT ANALYSIS OF INTERIOR SLAB-COLUMN CONNECTION REINFORCED WITH FRP BARS
}

Hamdy K. Shehab El-dein, Mohamed M. Husain, Youssef L. Zaki, Bahaa M. Gouda

\begin{abstract}
This paper describes the non-linear behavior of interior slab-column connection reinforced with fiber reinfo polymers (FRP) bars, under monotonically increasing vertical loads. The non-linear 3D finite element (FE) al program (ANSYS $\mathrm{V}^{13}$ ) [1] is used. A full scale interior slab column connection measuring $2500 \times 2500 \mathrm{~mm}$ supported over its perimeter line located at $250 \mathrm{~mm}$ from edges was subjected to th present analysis. Two bars were used, namely glass fiber reinforced polymers (GFRP) and carbon fiber reinforced polymers (CFR behavioris studied in comparison to reference models reinforced with conventional steel bars. A total of 35 column connection models were constructed and tested up to failure. The studied parameters are; i) tensic reinforcement ratios $(0.48$ to $1.74 \%)$; ii) compresion reinforcement ratios $(0.16$ to $0.41 \%)$; iii) concrete cr strength (28 to $60 \mathrm{MPa}$ ); iv) column size to slab depth ratio, (c/d), and v) slab depth (150 to $350 \mathrm{~mm}$ ). Tr the proposed FE model was verified against test results obtained byDuludeel [2]. Finally, a proposedequati punching shear resistance of slab reinforced with FRP barsis devised. The prediction of the proposed modif resistance equation is compared with current codes and other equations given in the literature, and is sho more accurate
\end{abstract}

